\title{
POTENCIALIDADE DO CAPIM ELEFANTE PARA PRODUÇÃO DE ETANOL DE SEGUNDA GERAÇÃO
}

\author{
A. R.C. MUNIZ, G. BERDET e L. da SILVA Universidade \\ Federal do Pampa, Curso de Engenharia Química \\ E-mail para contato: anamuniz@unipampa.edu.br
}

\begin{abstract}
RESUMO - Com o aquecimento global, decorrente da emissão de gases do efeito estufa, principalmente o $\mathrm{CO}_{2}$ gerado na queima de combustíveis fósseis, políticas mundiais têm apontado para a necessidade de produção de combustíveis utilizando produtos da fotossíntese. Uma nova fonte alternativa de matéria-prima para a produção de etanol é o capim elefante (Pennisetum purpureum), que é uma gramínea de grande porte, fácil manejo e cultivo e abundante em todo o Brasil. Este trabalho teve como objetivo, determinar a potencialidade do capim elefante, colhido pela Embrapa Pecuária Sul (CPPSul) no município de Bagé no estado do Rio Grande do Sul, para a produção de álcool de segunda geração. Para isso, a biomassa foi caracterizada por análise granulométrica, apresentando diâmetro médio de Sauter de 0,432 mm e, quimicamente, pelo método de Van Soest, que mostrou que a fração de capim elefante com maior potencial para a produção de etanol é a de folhas jovens com 22,01\% de hemicelulose, 52,28\% de celulose e $8,28 \%$ de lignina.Foram testados três tipos de pré-tratamento: ácido, hidrotérmico e básico, seguidos de hidrólise enzimática com a enzima comercial Celluclast ${ }^{\circledR}$ 1,5 L. O melhor resultado encontrado pelo método de 3,5-dinitrosalicilico (DNS) foi $1,94 \mathrm{~g} / \mathrm{L}$ de açúcares redutores obtido com pré-tratamento alcalino usando hidróxido de sódio $0,25 \mathrm{M}$. Esse resultado também foi encontrado em análise morfológica preliminar por microscopia óptica.
\end{abstract}

\section{INTRODUÇÃO}

O Brasil é o pioneiro no uso de biocombustíveis e atualmente produz etanol de primeira geração a partir de cana de açúcar, e, de segunda geração usando o bagaço e a palha da cana, sendo produzido comercialmente desde 2014 pela empresa Raízen (Raízen, 2014). Estados de clima subtropical, como o Rio Grande do Sul, importam $100 \%$ do etanol (Esber, 2014), sendo necessária a busca por novas biomassas, dentre as quais, o capim elefante é uma alternativa.

O capim elefante tem sido analisado como potencial fonte de biomassa para produção de etanol por poucos autores, cujas pesquisas mostram a necessidade de otimizar as condições de operação para melhorar a eficiência da produção de etanol, especialmente na etapa de prétratamento da biomassa (Usberti et al., 1988; Cardona et al., 2013; Menegol et al., 2014). Vários tipos de pré-tratamento têm sido usados com a finalidade de alterar ou remover a lignina, aumentar a área superficial e diminuir o grau de polimerização e cristalinidade da celulose visando facilitar a digestão enzimática (Canilha et al., 2010). Os métodos de pré- 
tratamento que têm demonstrado ser mais promissores e de custo adequado são: ácido diluído, explosão a vapor não catalisada, hidrotérmico com $\mathrm{pH}$ controlado, tratamento com cal e tratamento com amônia (Ramirez, 2010 apud Pinto, 2010). Segundo Cardona et al. (2013), no pré-tratamento ácido utilizando ácido diluído, as alterações nas composições das fases sólidas são devidas à hidrólise da hemicelulose e, em menor proporção, à hidrólise da celulose e no pré-tratamento alcalino, as alterações são devidas principalmente à remoção de lignina e, em menor proporção, pela hidrólise da fração celulósica e hemicelulósica, levando à diminuição no peso do sólido recuperado após o pré-tratamento. $\mathrm{O}$ melhor resultado encontrado usando capim elefante como biomassa foi para pré-tratamento alcalino com $\mathrm{NaOH} 1,5 \%(\mathrm{~m} / \mathrm{m})$ durante $1 \mathrm{~h}$ a $121^{\circ} \mathrm{C}$, obtendo $88,4 \%$ de remoção de lignina.

Após o pré-tratamento a biomassa lignocelulósica foi submetida à hidrólise para quebra das ligações glicosídicas da celulose, produzindo açúcares básicos e glicose, que podem ser fermentados pelo mesmo processo que os insumos de primeira geração. Segundo Fuentes (2009), a hidrólise enzimática tem se apresentado como uma das alternativas mais adequadas para a produção de açúcares a partir de biomassas lignocelulósicas, pois utiliza condições suaves durante o processo, o que leva a uma menor quantidade de subprodutos tóxicos na fermentação, além de produzir maiores rendimentos em glicose. $\mathrm{O}$ autor mostrou que a hidrólise enzimática é afetada por diferentes fatores, tais como: temperatura, tempo, $\mathrm{pH}$, carga enzimática, concentração de substrato, concentração de produtos e características estruturais da biomassa.Cardonaet al. (2013) hidrolisou capim elefantecom a enzima Accellerase 1500 obtendo 146,9 mg de açúcares redutores/g de biomassa.

\section{MATERIAIS E MÉTODOS}

A biomassa testada foi o capim elefante, colhido pela CPPSul, localizada no município de Bagé no Estado do Rio Grande do Sul. O capim elefante foi separado em dois lotes, um composto de plantas jovens e outro de plantas mais velhas, das quais se cortam as folhas e as mesmas crescem na safra seguinte. Em cada lote foram separadas as folhas do caule. Os ensaios de pré-tratamento e hidrólise foram realizados com a fração composta de folhas jovens, por apresentar maiores concentrações de celulose.

\subsection{Caracterização da biomassa}

A caracterização física da biomassa foi feita por meio das operações de secagem, moagem e peneiramento. A secagem foi conduzida em uma sala fechada com três desumidificadores de ar, seguindo a norma NREL/TP-510-42620. A amostra foi espalhada sobre jornais, respeitando a altura máxima de $0,15 \mathrm{~m}$, onde permaneceu em secagem natural até peso constante. A biomassa foi revirada uma vez por dia para não sofrer a ação de microrganismos decompositores durante o período experimental (HAMES, 2008). Procedeuse, então, a moagem que, segundo NREL/TP-510-42620, deve ocorrer em moinho de facas deixando a biomassa com medidas de 1 a $2 \mathrm{~cm}^{2}$. Em seguida, foi realizada análise granulométrica, com peneiras na faixa de 20 a 140 Tyler, submetidas à agitação durante 15 minutos.

A determinação da composição da biomassa em celulose, hemicelulose e lignina foi realizada usando o método de Van Soest. Esse método baseia-se na separação das diversas 
frações da biomassa por meio de reagentes específicos denominados detergentes: fibra em detergente neutro (FDN) e fibra em detergente ácido (FDA), previamente preparados como mostrado em Nogueira (2005). Inicialmente, foi adicionada à amostra $100 \mathrm{ml}$ da solução de FDN e, em seguida, encaminhada para um digestor, onde a mistura foi fervida por 60 min, resfriada a temperatura ambiente e filtrada a vácuo em cadinhos de vidro borossilicato, previamente secos a $105^{\circ} \mathrm{C}$ e pesados. A torta final foi lavada com água a $80{ }^{\circ} \mathrm{C}$, até duas vezes seu volume, seguida de lavagem com acetona. Os cadinhos foram conduzidos para secagem em estufa a $105^{\circ} \mathrm{C}$ por 8 horas e, em seguida, resfriados em dessecador e pesados. A massa resultante (\% FDN) constituiu-se basicamente de celulose, hemicelulose, lignina e de proteína, já separada das gorduras, dos carboidratos solúveis, da pectina e de outros constituintes solúveis em água, que compõem a parede celular. Numa segunda etapa, foi realizada a determinação do teor de fibras solúveis em detergente ácido usando procedimento experimental similar àquele para determinação de FDN, somente trocando o detergente FDN por FDA. O resíduo resultante (\% FDA), era constituído da porção menos digerível da parede celular, e em sua quase totalidade, composto de lignina e celulose. A separação da lignina foi realizada solubilizando a amostra, presente nos cadinhos contendo o resíduo da análise FDA, com $\mathrm{H}_{2} \mathrm{SO}_{4} 72 \%$ em quantidade suficiente para cobrir a amostra e formar uma pasta úmida. Em seguida, foi feita a quebra dos grumos com bastão de vidro, e, após três horas, iniciou-se a filtração seguida de lavagem com água destilada a $80^{\circ} \mathrm{C}$ até neutralizar o $\mathrm{pH}$. Após, os cadinhos foram inseridos em estufa a $105^{\circ} \mathrm{C}$ por 8 horas, deixados esfriar em dessecador, e pesados para obtenção da massa de lignina. Foram então inseridos em mufla a $450{ }^{\circ} \mathrm{C}$ por 4 horas, resfriados em dessecador e pesados novamente. O percentual de celulose, contido na amostra, foi calculado por diferença de massa, antes e após inserir os cadinhos na mufla.

\subsection{Pré-Tratamentos e Hidrólise}

O pré-tratamento tem a função de separar as estruturas poliméricas, que dão rigidez às células vegetais, como a lignina e a hemicelulose e, expor a celulose para posterior hidrólise enzimática e conversão para glicose. Foram realizados quatro ensaios em duplicata com quatro tipos diferentes de solventes para o pré-tratamento: hidróxido de sódio $0,25 \mathrm{M}$, hidróxido de potássio $0,01 \mathrm{M}$, ácido sulfúrico $5 \%(\mathrm{v} / \mathrm{v})$, e água destilada. O procedimento experimental consistiu na adição de $2 \mathrm{~g}$ de capim elefante (folhas jovens), previamente triturado e seco, em um béquer ao qual foram adicionados $20 \mathrm{ml}$ do solvente. Os béqueres foram tampados e levados para autoclave por $30 \mathrm{~min}$ a $123{ }^{\circ} \mathrm{C}$. Após esse tempo, cada amostra foi filtrada com água, até atingir $\mathrm{pH}$ neutro, secadas em estufa com ventilação forçada, na temperatura ambiente, por $24 \mathrm{~h}$ e por fim, armazenadas em geladeira. Cada amostra foi analisada posteriormente, por microscopia óptica, a fim de verificar o efeito de cada pré-tratamento sobre a estrutura celular mais externa do capim elefante.

Para cada pré-tratamento testado, foi realizado o seguinte procedimento de hidrólise. Em erlenmeyer de $125 \mathrm{ml}$, adicionou-se $0,5 \mathrm{~g}$ da amostra de capim elefante pré-tratado, $0,04 \mathrm{~g}$ de azida sódica e $4,6 \mathrm{ml}$ do complexo de enzimas Celluclast $1,5 \mathrm{~L}^{\circledR}$. Acrescentou-se solução tampão de citrato de sódio, até $45 \mathrm{ml}$, e transferiu-se para um banho termostático agitado, previamente aquecido a $50{ }^{\circ} \mathrm{C}$, onde permaneceu por $72 \mathrm{~h}$. Nesse período, foram realizadas diversas coletas de $3 \mathrm{ml}$ que foram armazenadas em geladeira para posterior análise de açúcares redutores, pelo método do DNS. Esse método fundamenta-se no fato de que os 
monossacarídeos, a glicose e a frutose são açúcares redutores, por possuírem grupo carbonílico e cetônico livres, que são capazes de se oxidar na presença de agentes oxidantes em soluções alcalinas. Um oxidante forte, comumente utilizado, é o ácido 3,5 dinitrosalicilico (DNS). A determinação de açúcares redutores foi realizada adicionando, em um tubo de ensaio de $10 \mathrm{~mL}, 1 \mathrm{ml}$ da amostra e $0,5 \mathrm{ml}$ do reagente DNS, e submetendo a mistura a banho maria na temperatura de $100{ }^{\circ} \mathrm{C}$ por 5 min, e em seguida, completando seu volume com água destilada. Para cada amostra foi medida a absorbância no comprimento de onda de $600 \mathrm{~nm}$.

\section{RESULTADOS E DISCUSSÃO}

O ensaio de peneiras permitiu o cálculo do diâmetro médio de Sauter de 0,432 mm, considerada a dimensão média das partículas presentes nas amostras de capim elefante. Os resultados obtidos pelo método de Van Soest são mostrados na Tabela 1 para os lotes de caule velho(A), folha velha (B), caule jovem (C) e folha jovem (D).

Tabela 1-Composição química de diferentes amostras de capim elefante

$$
\text { Estudo Material \%Massa } \quad \begin{aligned}
& \text { \% } \\
&
\end{aligned} \quad \text { Lignina } \% \text { Celulose } \% \text { Hemicelulose }
$$

Seca

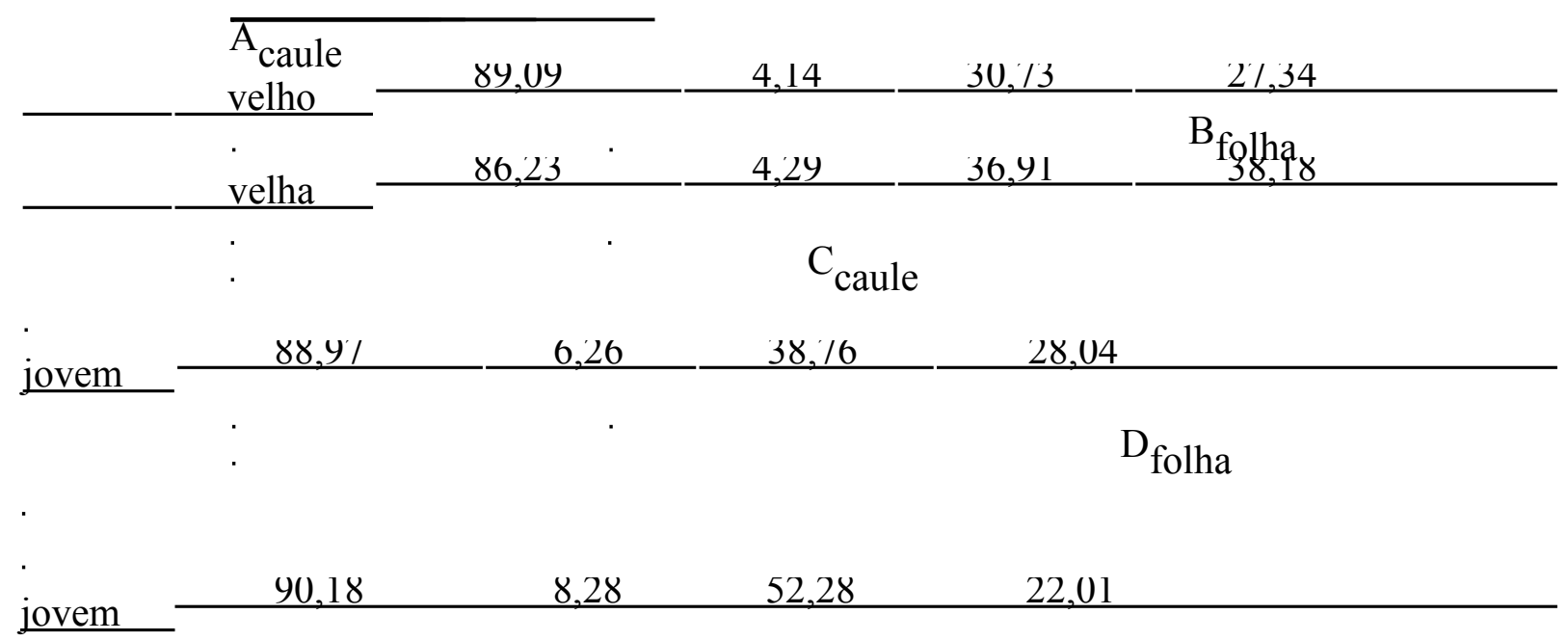

As composições mássicas do capim elefante encontradas nesse trabalho, com respeito à celulose e hemicelulose, potenciais fontes para a produção de etanol, foram comparáveis às descritas por Canilha et al. (2007) para o bagaço de cana de açúcar in natura $(46,86 \%$ de celulose e $27,50 \%$ de hemicelulose). Em todas as amostras, os mais elevados teores foram de celulose, variando de 30,73\% para caule velho (A) até 52,28\% para folhas jovens (D), mostrando que existe diferença na composição de cada parte componente do capim elefante, informação inovadora não encontrada na literatura. Segundo Fuentes, 2009, os açúcares redutores compreendem, além da glicose, também as pentoses presentes na hemicelulose, cuja maior concentração foi encontrada na amostra de folhas velhas (B). Porém, foi escolhida a amostra (D) para ser pré-tratada e hidrolisada, pois foi a que apresentou maior teor de celulose, componente presente em maior concentração no capim. Os resultados da hidrólise são exibidos na Figura 1, que mostra a variação da concentração de açúcares redutores em função do tempo. O pré-tratamento com $\mathrm{NaOH} 0,25 \mathrm{M}$ produziu a maior concentração de açúcares redutores, 1,94 g/L no tempo e 1860 minutos. Esse resultado foi confirmado pela 
análise morfológica preliminar realizada nas amostras antes (Figura 2A) e após cada prétratamento, onde observou-se que a maior desestruturação da parede celular ocorreu com o 
pré-tratamento alcalino usando $\mathrm{NaOH}$ 0,25 M (Figura 2B). O pré-tratamento ácido não foi tão efetivo na deslignificação da amostra, podendo ser ainda observadas partes intactas da estrutura da parede celular, o mesmo ocorrendo com o pré-tratamento hidrotérmico.

Figura 1 -Hidrólise de capim elefante para diferentes tipos de pré-tratamento.

2,5

2

1,5

1

0,5

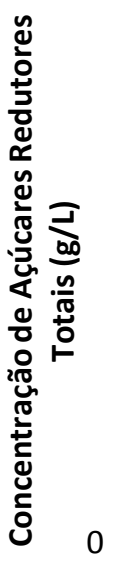

0

1000

2000

3000

$\mathrm{NaOH}$

$\mathrm{KOH}$

$\mathrm{H} 2 \mathrm{SO} 4$

$\mathrm{H} 2 \mathrm{O}$

Tempo ( $\mathrm{min}$ )

Figura 2: Micrografias da amostra sem pré-tratamento (A), compré-tratamento alcalino com $\mathrm{NaOH}(\mathrm{B})$ e com pré-tratamento ácido (C), todas em um aumento de 40x.

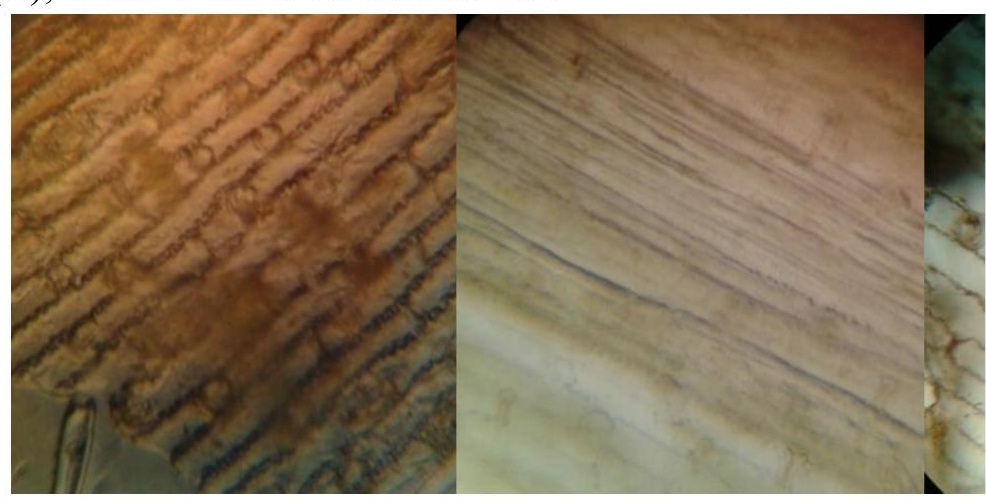


O capim elefante estudado mostrou que a parte composta por folhas jovens apresentou maior potencial para a produção de álcool, com teor de celulose comparável ao do bagaço de cana de açúcar, usado comercialmente para a produção de etanol de segunda geração. O prétratamento alcalino com $\mathrm{NaOH} 0,25 \mathrm{M}$ produziu a maior concentração de açúcares redutores e também a maior deslignificação, segundo mostraram as análises de ATR e de micrografias, respectivamente. 


\section{REFERÊNCIAS}

CANILHA, L., MilAGRES, A. M. F., SILVA, S. S., SilVA, J. B. A., FELIPE, M. G. A.,ROCHA, G. J. M., FERRAZ, A., CARVALHO, W. Sacarificação da biomassalignocelulósica através de pré-hidrólise ácida seguida por hidrólise enzimática: uma estratégia de "desconstrução" da fibra vegetal. RevistaAnalytica, n. 44. 2010.

CANILHA, L.; CARVALHO, W.; ROCHA, G.J.M.; ALMEIDA E SILVA, J. B.; GIULIETTI, M. Caracterização do bagaço de cana-de-açúcar in natura, extraído com etanol ou ciclohexano/etanol. In: XLVII CONGRESSO BRASILEIRO DE QUÍMICA, 2007. Natal. Disponível em: <http://www.abq.org.br/cbq/2007/trabalhos/11/11-570713.htm>. Acessoem: 22 de fev. 2015.

CARDONA, E.; RIOS, J.; PENA, J.; RIOS, L. Effects of the pretreatment method on enzymatic hydrolysis and ethanol fermentability of the cellulosic fraction from elephant grass. Fuel, v. 118, p. 41-47, 2013.

ESBER, C. Vem aí o etanol de arroz. Disponível em: http://www.amanha.com.br/index.php?option=com_content\&view=article\&id=6481:ve m-ai-o-etanol-de-arroz\&catid=34:home-1\&Itemid=67. Acesso em: 19 jan. 2015.

FUENTES, L. L. G. Determinação de dados cinéticos da deslignificação do bagaço. 2009. 149p. Dissertação de Mestrado -Faculdade de Engenharia Química, Universidade Estadual de Campinas.Campinas, 2009.

HAMES, B. Preparation of samples for compositional analysis: Laboratory Analytical Procedure (LAP). National Renewable Energy Laboratory, Technical Report, NREL/TP-510-42620, 9 p., 2008.

MENEGOL, D.; SCHOLL, A. L.; FONTANA, R. C.; DILlON, A. J. P.; CAMASSOLA, M.Potential of a penicilliumechinulatum enzymatic complex producedin either submerged or solid-state cultures for enzymatic hydrolysisof elephant grass. Fuel, v. 133, p. 232-240, 2014.

NOGUEIRA, A, R.; SOUSA, G. B. Manual de Laboratórios: Solo, água, nutrição vegetal, nutrição animal e alimentos. São Carlos. Editora: EmbrapaPecuária Sudoeste, 2005.

PINTO, F. H. P. B. Etanol celulósico: um estudo de viabilidade econômico-financeira.2010. 78p. Dissertação de Mestrado - Escola de Economia de São Paulo, FGV-EESP, Empresa Brasileira de Pesquisa Agropecuáriae Escola Superior de Agricultura "Luis de Queiroz”, ESALQ/USP.São Paulo, 2010.

RAÍZEN. Tecnologia em energia renovável: etanol de segunda geração. Disponível em:http://www.raizen.com.br/energia-do-futuro-tecnologia-em-energiarenovavel/etanol-de-segunda-geracao. Acesso em: 17 fev. 2015.

USBERTI, J. A. F.; TEIXEIRA, J. P. F.; GALLO, P. B.; PEREIRA, C. A. Produção de etanol de gramíneas forrageiras tropicais. Pesq.Agropec. Bras., Brasília, v. 23(2), p. 175-187, 1988. Disponível em: $<$ http://seer.sct.embrapa.br/index.php/pab/article/view/13796>. Acesso em 22 de fev. 2015. 